\title{
Symptoms, lactate and exercise limitation at peak cycle ergometry in adults with cystic fibrosis
}

\author{
A.J. Moorcroft*, M.E. Dodd", J. Morris ${ }^{\oplus}$ and A.K. Webb"
}

ABSTRACT: The purpose of this study was to investigate symptoms, lactate accumulation and limiting factors at peak exercise in cystic fibrosis (CF) patients.

In total, 104 CF adults attending an adult CF centre and 27 controls performed progressive cycle ergometry to a symptom-limited maximum. Measurements taken at peak exercise included: heart rate, ventilation, oxygen uptake, carbon dioxide output, oxygen saturation and blood lactate. Symptom scores of perceived breathlessness and muscle effort were recorded using Borg scales.

The CF subjects had a lower mean body mass index, forced expiratory volume in one second (FEV 1$)$ and peak oxygen uptake than controls. Peak lactate concentrations were very similar to controls (mean $\pm \mathrm{SD} \quad 6.8 \pm 2.0 \mathrm{mmol} \cdot \mathrm{L}^{-1}$ versus $7.4 \pm 1.0 \mathrm{mmol} \cdot \mathrm{L}^{-1}$ ). Symptom scores were no different to controls for either breathlessness $(4.5 \pm 2.0$ versus $4.3 \pm 1.0)$ or perceived muscle effort $(6.1 \pm 2.0$ versus $6.5 \pm 1.0)$, with higher scores for muscle effort than breathlessness in both groups. In addition, peak ventilation was lower than the predicted maximum, and high peak heart rates were recorded supporting nonpulmonary factors as important in limiting peak exercise. Peak oxygen uptake was correlated with FEV1.

Comparison of CF subjects with mild or moderate pulmonary disease and controls revealed similar exercise responses. In contrast, those CF patients with severe lung disease (FEV $1<40 \%$ predicted) had significantly higher breathlessness, lower muscle effort scores, lower peak lactate, lower peak heart rate and a mean ventilation exceeding predicted, thus confirming that ventilation was the major factor limiting exercise.

In conclusion, cystic fibrosis subjects have a reduced peak exercise capacity, but their exercise response is similar to controls in generating high blood-lactate concentrations and symptoms of muscle effort in excess of dyspnoea. Nonpulmonary factors influence peak performance more in those without severe disease.

KEYWORDS: Cystic fibrosis, dyspnoea, exercise, lactate, muscle effort, symptom limitation

$\mathbf{R}$ ecently, two seminal papers have shown preservation of pulmonary function in children and adults with cystic fibrosis (CF) undertaking long-term domiciliary exercise $[1,2]$, and highlighted the importance of exercise as an important modality in the management of $\mathrm{CF}$. Peak exercise performance is reduced in patients with CF [1-10]. Pulmonary function correlates with peak aerobic and anaerobic exercise capacity [810], and this relationship has been interpreted as indicating a pulmonary limitation to exercise in CF. Exercise performance is, however, influenced by many factors, amongst which nutritional status [11-13] and peripheral muscle function [6-7, 14] have been demonstrated to have strong correlates with peak performance in $\mathrm{CF}$.
Encouraging exercise to be a part of therapy and maintaining research in this area are important, as there are still many gaps in the understanding of exercise performance in CF.

Lactate accumulation is a marker of peripheral muscle anaerobic metabolism and fatigue [15]. However, there is little data concerning lactate accumulation during exercise in $\mathrm{CF}$, although several small studies in subjects with milder disease have shown that lactate accumulation occurs [16-19]. There is very little information concerning symptom limitation during exercise in CF. Usually, exercise terminates when the symptoms experienced during progressive exercise reach an intensity greater than which the

\section{AFFILIATIONS}

${ }^{*}$ The Royal Shrewsbury Hospital, Shrewsbury, and

\#Manchester Adult CF Centre, and 'Dept of Medical Statistics, South Manchester University Hospitals NHS Trust, Wythenshawe Hospital, Manchester, UK.

CORRESPONDENCE

A.K. Webb

Manchester Adult Cystic Fibrosis Centre

Wythenshawe Hospital

South Manchester

M23 9LT

UK

Fax: 441612912080

E-mail: the5webbs@hotmail.com

Received:

January 272004

Accepted after revision:

February 032005

SUPPORT STATEMENT

This study was supported by the CF Research Trust (Bromley, UK) 
person is prepared to tolerate. Studies in subjects with chronic obstructive pulmonary disease (COPD) have shown that, despite pulmonary impairment, subjects tended to experience a greater sense of peripheral muscle effort than dyspnoea [20].

The objectives of the current study were to examine the limiting symptoms of breathlessness, muscle fatigue perception and blood-lactate accumulation at peak exercise in CF. In addition, the current authors sought to establish the relative importance of pulmonary function, peripheral muscle function and specific symptoms that limit peak exercise in CF adults for different levels of disease severity. It was hypothesised that dyspnoea would be greatest in those with severe pulmonary dysfunction and that symptoms of peripheral muscle effort would predominate in those with mild pulmonary disease. A correlation between peak blood-lactate levels and pulmonary disease severity was also anticipated, with reduced levels seen in those with a marked ventilatory limit to exercise.

\section{METHODS}

\section{Subjects}

In total, 104 adults with CF were recruited from the Manchester Adult CF centre (Manchester, UK) to perform a symptom-limited peak exercise test. Twenty-seven normal controls of a similar age who were free from respiratory disease or musculoskeletal disease were also recruited from the hospital staff and visitors. Subjects were initially familiarised with the exercise equipment and symptom scoring, and were then instructed to perform progressive exercise to a symptom-limited maximum using an electronically braked cycle ergometer (Rodby electronic RE830; Rodby, Sodertalje, Sweden). A ramp protocol was used with an incremental rate of $8-25 \mathrm{~W} \cdot \mathrm{min}^{-1}$ judged by an operator, according to disease severity and likely fitness, with the aim for a test duration of approximately $8 \mathrm{~min}$. Subjects breathed through a mouthpiece and pneumotachograph connected with a sample line to a computerised breath-by-breath analyser (CPX; Medical Graphics, St Paul, MN, USA). The pneumotachograph was calibrated before each individual test, and the gas analyser underwent a temperature, barometric pressure and two-point gas calibration before each exercise testing session. Peak exercise measurements were recorded as the mean from the final eight breaths prior to the termination of exercise. The peak exercise variables were: respiratory rate; minute ventilation $\left(V^{\prime} \mathrm{E}\right)$; oxygen uptake $\left(V^{\prime} \mathrm{O}_{2}\right)$; carbon dioxide output $\left(V^{\prime} \mathrm{CO}_{2}\right)$ and end-tidal $\mathrm{CO}_{2}$ pressure $\left(P \mathrm{ET}, \mathrm{CO}_{2}\right)$. Heart rate $(\mathrm{HR})$ was measured using a cardiac monitor ( $\mathrm{S}$ and $\mathrm{W}$, Albertslund, Denmark), and arterial oxygen saturations $\left(\mathrm{S}_{\mathrm{a}}, \mathrm{O}_{2}\right)$ were recorded at rest and peak exercise using a pulse oximeter (BIOX 7300a; Ohmeda, Louiseville, KY, USA). Immediately at the end of exercise, subjects were asked to score their sense of breathlessness and muscle effort/fatigue at peak exercise using Borg scales [21]. Whole blood lactate was measured at the end of exercise from a finger-prick capillary sample taken $1 \mathrm{~min}$ after the end of exercise. An immediate lactate analysis was performed using an enzymatic method (Analox GM7; Analox Instruments Ltd, London, UK).

Height, weight and spirometry (Vitalograph, Buckingham, UK) were measured prior to exercise testing. The forced expiratory volume in one second (FEV1) and forced vital capacity were expressed as a percentage of predicted normal values [22]. The predicted peak HR (HRpeak) was calculated from age, and the predicted peak $V^{\prime} \mathrm{O}_{2} \quad\left(V^{\prime} \mathrm{O}_{2}\right.$,peak $)$ was calculated from age, sex, height and weight [23]. Body mass index (BMI) was calculated $\left(\mathrm{kg} \cdot \mathrm{m}^{-2}\right)$ as an index of nutritional status. Ventilation was expressed as a percentage of predicted maximal voluntary ventilation $\left(V^{\prime} \mathrm{E} / \mathrm{MVV}\right)$. The predicted MVV was calculated as $35 \times \mathrm{FEV} 1$ [23]. Ventilation was also expressed relative to $\mathrm{CO}_{2}$ output as the ventilatory equivalent for $\mathrm{CO}_{2}\left(V^{\prime} \mathrm{E} / V^{\prime} \mathrm{CO}_{2}\right)$. Ethical approval for the study protocol was received from the hospital research ethics committee (South Manchester University Hospital, Manchester, UK), and informed consent provided by participants.

\section{Statistical analysis}

The relationships between variables were analysed using Spearman rank correlation. Comparisons between the CF and the control subjects were made with unpaired t-tests because all outcome variables were found to follow approximately normal distributions. A one-way ANOVA was used to compare the responses to exercise in CF subjects with differing degrees of pulmonary disease severity and controls. The CF subjects were divided into those with mild (FEV1 $>60 \%$ pred), moderate (FEV1 $40-60 \%$ pred) or severe (FEV1 $<40 \%$ pred) pulmonary disease. Post hoc comparisons were made using a Scheffe test. A two-tailed p-value of $<0.05$ was taken to indicate statistical significance.

\section{RESULTS}

Summary characteristics of the CF adults (63 male, 41 female) and controls (16 male, 11 female) are shown in table 1 . For the

\begin{tabular}{|c|c|c|c|}
\hline \multirow[t]{2}{*}{ TABLE 1} & \multicolumn{3}{|c|}{$\begin{array}{l}\text { Characteristics of cystic fibrosis (CF) adults } \# \text { and } \\
\text { controls }\end{array}$} \\
\hline & CF & Controls & p-value \\
\hline Age yrs & $24.6 \pm 7.1$ & $26.0 \pm 4.7$ & \\
\hline BMI $\mathbf{k g} \cdot \mathrm{m}^{-2}$ & $20.5 \pm 2.0$ & $23.8 \pm 2.0$ & $<0.001$ \\
\hline FEV $_{1} \%$ pred & $53.5 \pm 21.4$ & $102 \pm 10.9$ & $<0.001$ \\
\hline FVC $\%$ pred & $74.6 \pm 21.4$ & $100.7 \pm 12.5$ & $<0.001$ \\
\hline$V^{\prime} \mathrm{O}_{2}$, peak $\%$ pred & $64.0 \pm 16.3$ & $94.6 \pm 13.0$ & $<0.001$ \\
\hline $\mathrm{Sa}, \mathrm{O}_{2}$, rest $\%$ & $96.8 \pm 2.0$ & $98.7 \pm 1.0$ & $<0.001$ \\
\hline $\mathrm{Sa}, \mathrm{O}_{2}$,peak $\%$ & $93.2 \pm 4.1$ & $96.7 \pm 1.0$ & $<0.001$ \\
\hline HRpeak \% pred & $85.0 \pm 7.1$ & $93.4 \pm 4.2$ & $<0.001$ \\
\hline$V^{\prime} E / M V V \%$ & $92.0 \pm 22.4$ & $66.9 \pm 16.6$ & $<0.001$ \\
\hline$V^{\prime} \mathrm{E} / V^{\prime} \mathrm{CO}_{2}$ & $31.7 \pm 4.1$ & $28.4 \pm 3.6$ & $<0.001$ \\
\hline RR breaths $\mathrm{min}^{-1}$ & $41.0 \pm 9.2$ & $39.0 \pm 8.3$ & 0.30 \\
\hline $\mathrm{PET}, \mathrm{CO}_{2} \mathrm{mmHg}$ & $43.2 \pm 6.1$ & $42.7 \pm 5.7$ & 0.70 \\
\hline Lactate $\mathrm{mmol} \cdot \mathrm{L}^{-1}$ & $6.8 \pm 2.0$ & $7.4 \pm 1.0$ & 0.13 \\
\hline \multicolumn{4}{|l|}{ Borg scores } \\
\hline Breathlessness & $4.5 \pm 2.0$ & $4.3 \pm 1.0$ & 0.62 \\
\hline Muscle fatigue & $6.1 \pm 2.0$ & $6.5 \pm 1.0$ & 0.31 \\
\hline
\end{tabular}


CF subjects, there was a wide age range (16-49 yrs), BMI (14.6$\left.26.6 \mathrm{~kg} \cdot \mathrm{m}^{-2}\right)$ and FEV1 (16.5-111\% pred).

A mean peak lactate concentration of $6.8 \pm 0.2 \mathrm{mmol} \cdot \mathrm{L}^{-1}$ (range 2.8-11.6) was achieved in the CF population and this was not significantly different from that observed in the control population. The relatively high mean HRpeak observed in the CF subjects confirmed that considerable cardiocirculatory stress occurred. The mean peak ventilation was less than the predicted MVV $(92.0 \pm 2.2 \%)$, thus suggesting that a pure ventilatory limit was not generally reached. There was a small $(-3.6 \%)$ but significant $(\mathrm{p}<0.001)$ fall in mean $\mathrm{Sa}_{2} \mathrm{O}_{2}$ from rest to peak exercise in the CF subjects, which exceeded that seen in the controls $(-2.0 \%)$. The mean $\mathrm{Sa}_{1} \mathrm{O}_{2}$ at peak exercise was lower in the CF subjects than in the controls (93.2 versus $96.7 \%$ ). Only $15(14 \%)$ of 104 subjects with CF desaturated to $<90 \%$ at peak exercise with two of these to $<80 \%$.

For the group as a whole, there was no difference in symptom scores (table 1), although the mean Borg breathlessness score of $4.5 \pm 2.0$ in the CF group was lower than the mean muscle effort score of $6.1 \pm 2.0$. Almost identical mean symptom scores were observed in the control group. Of the $104 \mathrm{CF}$ subjects, 78 rated muscle effort greater than breathlessness, 15 rated breathlessness greater than muscle effort and 11 subjects rated both equally. The subjects' perceptions were, therefore, consistent with the physiological measurements in indicating that nonpulmonary factors were of importance in limiting peak exercise.

\section{Relationships between variables}

Table 2 displays the correlations of $V^{\prime} \mathrm{O}_{2}$,peak, lactate and symptom scores with some of the other exercise variables. FEV1 and $V^{\prime} \mathrm{O}_{2}$,peak were strongly correlated. The correlation of lung function with exercise capacity is much greater in those with more severe pulmonary dysfunction.

Peak lactate was correlated with FEV1 (fig. 1), with reduced peak values in those with the very lowest values of FEV1 $(\mathrm{r}=0.43 ; \mathrm{p}<0.001)$. Higher lactate concentrations tended to be recorded in those with the highest $V^{\prime} \mathrm{O}_{2}$,peak and $\mathrm{HR}$. The symptom scores correlated poorly with any other variable,

\begin{tabular}{|c|c|c|c|c|}
\hline \multirow[t]{2}{*}{ TABLE 2} & \multicolumn{4}{|c|}{$\begin{array}{l}\text { orrelations between exercise variables in cystic } \\
\text { orosis adults }\end{array}$} \\
\hline & $\begin{array}{l}V^{\prime} \mathrm{O}_{2} \text {,peak } \\
\% \text { pred }\end{array}$ & $\begin{array}{l}\text { Lactate } \\
\mathrm{mmol} \cdot \mathrm{L}^{-1}\end{array}$ & Breathlessness & $\begin{array}{l}\text { Muscle } \\
\text { fatigue }\end{array}$ \\
\hline FEV1 \% pred & $0.70^{\star \star \star}$ & $0.43^{* * *}$ & $-0.22^{*}$ & $0.22^{*}$ \\
\hline BMI $\mathbf{k g} \cdot \mathbf{m}^{-2}$ & $0.51^{\star \star \star}$ & $0.22^{*}$ & 0.02 & 0.15 \\
\hline HRpeak \% pred & $0.47^{\star \star \star}$ & $0.40^{* * *}$ & 0.10 & $0.21^{*}$ \\
\hline$V^{\prime} E / M V V \%$ & $-0.29 * \star$ & 0.16 & $0.37^{\star * *}$ & -0.04 \\
\hline RR breaths $\min ^{-1}$ & -0.11 & 0.14 & $0.26^{\star \star}$ & 0.07 \\
\hline Lactate $\mathrm{mmol} \cdot \mathrm{L}^{-1}$ & $0.51^{* * *}$ & & -0.02 & 0.16 \\
\hline
\end{tabular}

$V^{\prime} \mathrm{O}_{2}$ : oxygen uptake; \% pred: \% predicted; $F E V_{1}$ : forced expiratory volume in one second; BMI: body mass index; HR: heart rate; $V^{\prime} E$ : minute ventilation; $\mathrm{MVV}$ : maximum voluntary ventilation; RR: respiratory rate. ${ }^{*}: \mathrm{p}<0.05$; $*$ : $p<0.01 ;{ }^{* \star *}: p<0.001$.

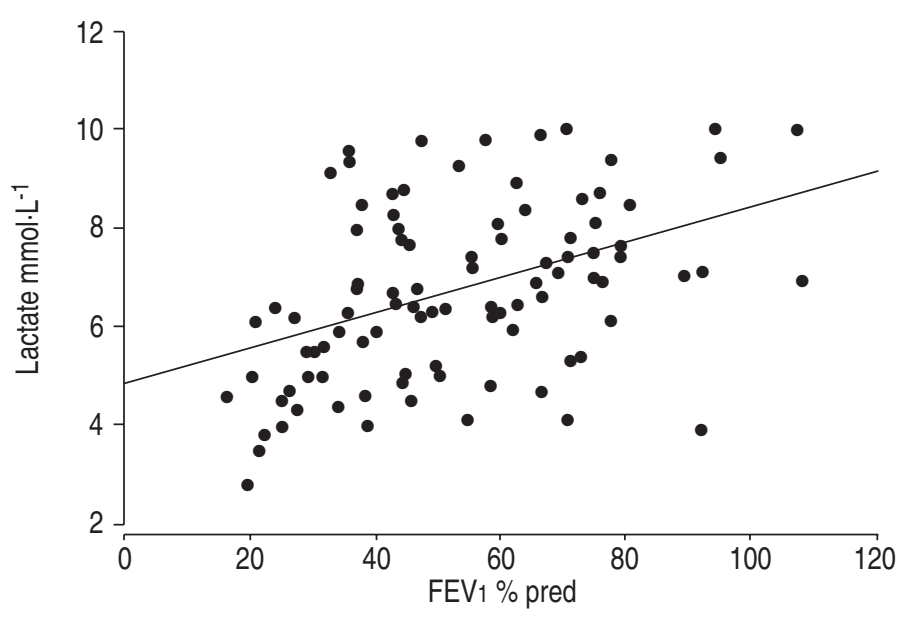

FIGURE 1. Peak blood lactate $\left(\mathrm{mmol} \cdot \mathrm{L}^{-1}\right)$ versus forced expiratory volume in one second ( $F E V_{1} ; \%$ predicted) for the 104 cystic fibrosis adults. $r=0.43$.

although a higher dyspnoea score was associated with ventilation assuming a greater proportion of predicted ventilatory capacity. The perceived intensities of dyspnoea and muscle effort were positively correlated with each other $(\mathrm{r}=0.40)$.

\section{Pulmonary disease severity and exercise performance}

Table 3 displays comparisons of CF subjects with severe (FEV1 $<40 \%$ pred), moderate (FEV1 $40-60 \%$ pred) and mild (FEV1 $>60 \%$ pred) pulmonary disease and normal controls. Those with severe pulmonary dysfunction had a significantly lower $\mathrm{BMI}$ and, thus, poorer nutritional status than those with mild or moderate disease.

It is noteworthy that those CF subjects with mild or moderate pulmonary dysfunction were more similar to the controls than to those subjects with severe disease. There was no significant difference in $\mathrm{PET}, \mathrm{CO}_{2}$, lactate or Borg scores of muscle effort and breathlessness between CF subjects with mild or moderate pulmonary dysfunction and controls. HRpeak was only a little lower and, whilst $V^{\prime} \mathrm{E} / \mathrm{MVV}$ was higher, it was still $<100 \%$, indicating that there was reserve ventilatory capacity. Peak $\mathrm{Sa}_{1} \mathrm{O}_{2}\left(\mathrm{Sa}_{1} \mathrm{O}_{2}\right.$, peak $)$ was a little lower in the CF subjects with moderate pulmonary dysfunction. Although peak oxygen uptake was reduced in CF patients with mild-to-moderate pulmonary dysfunction, symptom scores and lactate levels were the same as for normal controls.

Those with severe pulmonary disease had higher breathlessness and lower muscle effort scores than the other groups. In these subjects, however, the excess of muscle fatigue scores over breathlessness scores was small. Subjects also had a lower peak lactate, lower HRpeak and a mean ventilation exceeding MVV $(110 \pm 2.9 \%)$, thus suggesting that ventilation was becoming the limiting factor. A higher $P \mathrm{ET}, \mathrm{CO}_{2}$ was seen in the severe group, although only reaching statistical significance in comparison to the mild CF group. The severe group had a mean lactate of $5.7 \mathrm{mmol} \cdot \mathrm{L}^{-1}$ and a mean Borg score for muscle effort of 5.6, so muscle fatigue was evident even at a low FEV1. A greater degree of oxygen desaturation may have contributed to this, as a significantly lower mean $\mathrm{Sa}_{2} \mathrm{O}_{2}$,peak was 
TABLE 3 Mean values for cystic fibrosis (CF) subjects grouped according to pulmonary disease severity and controls

\begin{tabular}{|c|c|c|c|c|c|}
\hline & Severe & Moderate & Mild & Control & p-value \\
\hline Subjects $n$ & 33 & 33 & 38 & 27 & \\
\hline Age yrs & $27.8 \pm 8.0$ & $23.5 \pm 5.2^{\#}$ & $22.8 \pm 5.5^{\#}$ & $26.0 \pm 4.7$ & \\
\hline BMI $\mathbf{k g} \cdot \mathrm{m}^{-2}$ & $19.3 \pm 2.3$ & $20.4 \pm 1.7^{\circ}$ & $21.6 \pm 2.5^{\# \cdot \bullet}$ & $23.8 \pm 2.1^{\#}$ & $<0.001$ \\
\hline FEV $1 \%$ pred & $30.7 \pm 6.9^{+}$ & $49.4 \pm 6.3^{+}$ & $77.0 \pm 13.6^{+}$ & $102.0 \pm 10.9^{+}$ & $<0.001$ \\
\hline $\mathrm{Sa}_{\mathrm{a}} \mathrm{O}_{2}$,rest \% pred & $95.2 \pm 2.3$ & $97.4 \pm 1.7^{\# \cdot 9}$ & $97.7 \pm 1.2^{\#}$ & $98.7 \pm 1.0^{\circ}$ & $<0.001$ \\
\hline $\mathrm{Sa}, \mathrm{O}_{2}$, peak $\%$ & $89.6 \pm 5.2$ & $93.5 \pm 3.4^{\#, 9}$ & $95.9 \pm 1.8^{\#}$ & $96.7 \pm 1.0^{\#}$ & $<0.001$ \\
\hline HRpeak \% pred & $80.6 \pm 7.5$ & $87.3 \pm 5.7^{\#, \cdot 9}$ & $86.7 \pm 7.4^{\# \cdot 9}$ & $93.4 \pm 4.2^{\#}$ & $<0.001$ \\
\hline$V^{\prime} E / M V V \%$ & $110.0 \pm 16.6^{5}$ & $95.9 \pm 20.1^{\S}$ & $74.3 \pm 16.0$ & $66.9 \pm 16.6$ & $<0.001$ \\
\hline$V^{\prime} \mathrm{E} / V^{\prime} \mathrm{CO}_{2}$ & $32.0 \pm 4.0^{\circ}$ & $31.6 \pm 4.0^{\circ}$ & $31.4 \pm 4.3^{\circ}$ & $28.4 \pm 3.6$ & $<0.05$ \\
\hline RR breaths $\cdot \min ^{-1}$ & $42.1 \pm 8.6$ & $43.7 \pm 9.8^{f}$ & $37.6 \pm 8.0$ & $39.0 \pm 8.3$ & $<0.05$ \\
\hline Breathlessness & $5.0 \pm 1.7$ & $4.2 \pm 1.7$ & $4.2 \pm 2.5$ & $4.3 \pm 1.0$ & 0.24 \\
\hline Muscle fatigue & $5.6 \pm 2.3$ & $6.1 \pm 2.3$ & $6.5 \pm 2.5$ & $6.5 \pm 1.0$ & 0.16 \\
\hline
\end{tabular}

Data are presented as mean $\pm \mathrm{SD}$, unless otherwise stated. BMI: body mass index; FEV1: forced expiratory volume in one second; \% pred: \% predicted; FVC: forced vital capacity; $\mathrm{V}^{\prime} \mathrm{O}_{2}$ : oxygen uptake; $\mathrm{Sa}, \mathrm{O}_{2}$ : arterial oxygen saturation; $\mathrm{HR}$ : heart rate; $\mathrm{V}^{\prime} \mathrm{E}$ : minute ventilation; $\mathrm{MVV}$ : maximum voluntary ventilation; $\mathrm{V}^{\prime} \mathrm{CO}_{2}$ : carbon dioxide output; RR: respiratory rate; $\mathrm{PET}, \mathrm{CO}_{2}$ : end-tidal carbon dioxide pressure. Post hoc comparisons were made with Scheffe's test. \#: significantly different from severe $\mathrm{CF}$ group; ${ }^{*}$ significantly different from control group; ${ }^{+}$: all groups significantly different from each other; ${ }^{\varsigma}$ : all groups significantly different from each other, except for mild $\mathrm{CF}$ versus controls; ${ }^{f}$ : significantly different from mild CF group.

seen in the severe group, with 10 of the 33 subjects having a $\mathrm{Sa}_{\mathrm{a}} \mathrm{O}_{2}$, peak of $<90 \%$, with two of these desaturating to $<80 \%$.

\section{DISCUSSION}

In this study, the current authors found that, although peak aerobic capacity was reduced, the exercise response in CF subjects was strikingly similar to that of the controls. This was particularly true of peak lactate levels and exercise-limiting symptoms, areas that have received relatively little attention in the evaluation of exercise limitation in CF. The CF subjects achieved high blood-lactate concentrations at peak exercise and reported symptoms of muscle effort in excess of dyspnoea. These results occurred across the full range of pulmonary disease severity. In those patients with severe pulmonary disease, the breathlessness scores approximated more closely to the muscle effort scores, with little difference between the two. Blood-lactate concentrations at peak exercise were significantly lower in those with severe disease, but an elevated level was still recorded, even in the presence of pulmonary limitation. It was speculated that this may reflect a loss of cardiocirculatory/muscle capacity in parallel with the decline in respiratory function.

Several smaller studies have included lactate measurement in the assessment of peak exercise, and have shown that $\mathrm{CF}$ subjects do generate a rise in blood lactate on progressive exercise [16-19]. The present authors found raised lactate levels at peak exercise in CF patients across the full range of pulmonary disease severity, with those in the middle/ moderate group achieving very similar peak concentrations to controls. Therefore, CF patients can achieve considerable anaerobic metabolism at peak exercise. This implies that either the supply of oxygen to the exercising muscles or the ability of those muscles to utilise oxygen was nearing its limits. This is the case in normal subjects at peak exercise, but in the $\mathrm{CF}$ subjects this was occurring at lower work rates. The early occurrence of the "lactate threshold" during incremental exercise has been reported in patients with mild CF [18], and also in subjects with COPD [24]. The implication of the present lactate data is that CF patients with mild or moderate pulmonary disease are not limited by ventilation, but rather by nonpulmonary factors leading to muscle fatigue. This interpretation is supported by relatively high HRpeak being achieved and peak ventilation being lower than the predicted MVV. CF subjects with severe pulmonary dysfunction differ from those with less severe disease, but, despite their ventilatory limitation, lactate accumulation was recorded at peak exercise at a level that suggested increased peripheral muscle anaerobic metabolism in a large number of the severely affected patients.

It seems likely that oxygen desaturation played no substantial part in the reduced exercise capacity and lactate accumulation seen in the present CF subjects (except in those with severe disease). Only a minority of subjects desaturated to $<90 \%$ with exercise, but most of those who did desaturate significantly had an FEV $1<40 \%$. The current results are consistent with previous studies demonstrating that falls in $\mathrm{Sa}_{2} \mathrm{O}_{2}$ during exercise are associated with severe pulmonary disease [3, 25].

There is no data concerning the peripheral circulation in CF; however, oxygen delivery has not been shown to be a factor in 
the early lactic acidosis seen in patients with COPD [26]. The premature lactate rise during progressive exercise in COPD is correlated with reduced concentrations of glycolytic enzymes in skeletal muscle [27], and exercise training increased the lactate threshold and concentrations of muscle oxidative enzymes [28]. It may be that a similar situation applies in $\mathrm{CF}$, and peripheral muscle function is a more important factor than previously appreciated in the early onset of fatigue than cardiocirculatory or pulmonary factors.

The onset of blood-lactate accumulation during exercise is a marker of nonsustainable work rates being reached, and the work rate at which it occurs is a measure of fitness. The precise mechanisms by which blood-lactate accumulation occurs during exercise is unclear, but it is determined by many factors including: the mass of exercising muscle; supply of oxygen to that muscle in blood; diffusion into cells; and the efficiency of utilisation by those muscle cells.

The current study was not designed to examine muscle function other than by measurement of lactate as a marker of muscle fatigue/metabolic stress. There has been considerable debate since the mid 1990s about the biochemistry, quality, quantity and biofunction of $\mathrm{CF}$ muscle in mild and severe disease. Currently, there is no unifying hypothesis and recent publications describe differing results (vide infra). The relatively few direct studies of skeletal muscles in CF show abnormalities of function. A leftward shift in the forcefrequency response is seen in malnourished patients with $C F$, consistent with selective atrophy of type-2 (fast twitch) muscle fibres [29]. In vivo synthesis of adenoine triphosphate in exercising skeletal muscle has been shown to be reduced by $19-25 \%$ in adolescents with CF [30]. With regard to these two studies, it should be stated that they were undertaken in young patients whose muscles were still developing and some who were malnourished, and described changes would reflect loss of bulk rather than an intrinsic basic defect in CF muscle. In vitro studies have found impaired oxidative enzyme kinetics in CF as compared with controls [31, 32].

Recent work has suggested that reduced muscle performance may be due to impaired muscle function rather than just decreased muscle mass due to malnutrition. SELVADURAI et al. [6] showed that female CF athletes with good nutritional status and excellent pulmonary function have lower anaerobic power and leg strength than controls, although the daily activities of the CF athletes were higher than those of the controls. In addition, the CF female athletes had markedly different biochemical responses to exercise than controls at highintensity exercise. Specifically, the CF females did not develop a significant intracellular acidosis, suggesting a limited response of the muscles to maximal exercise. These findings support previous work that implicated inefficient oxidative mitochondrial metabolism in CF muscles [32]. A study by MOSER et al. [7] supported an intrinsic CF muscle defect, rather than just reduced muscle size, to account for the reduced exercise performance of $\mathrm{CF}$ subjects. Magnetic resonance imaging of the mid-thigh cross sectional area (CSA) was used, and it was found that, although CF subjects had the same CSA as controls, $V^{\prime} \mathrm{O}_{2}$, peak was reduced. In addition, in order to exclude results derived only from effort-dependent peak exercise, using the slopes of regression lines, Mosen et al. [7] examined dynamic variables during exercise and found indices of aerobic function were lower in CF subjects compared with controls.

Exercise capacity in CF subjects may also be determined by the class (severity) of the CF transmembrane conductance regulator (CFTR) mutation. SELVADURI et al. [33] found that CF subjects with a class I or II mutation (severe) had a lower peak aerobic capacity and anaerobic power compared with those with a class III, IV or V (less severe) CFTR mutation.

Two recent studies examined muscle strength using static isometric and dynamic isokinetic exercises in CF subjects and reported different results [34, 35]. HuSSEY et al. [34] found that $13 \mathrm{CF}$ children had reduced isokinetic strength compared with controls, but ELKIN et al. [35] found that, although a group of CF adults were weaker than controls due to reduced muscle bulk, when this was corrected, the CF adults had a similar force-generating capacity of their muscle, implying CF muscle quality was normal. These two studies used a small number of patients and did not examine CF muscle quality at a physiological or biochemical level, nor was the suggested reduced oxidative capacity of $\mathrm{CF}$ muscles discussed in the context of their findings.

Although evidence is beginning to indicate a basic defect in the muscle of CF subjects, there are clearly additional factors contributing to muscle weakness and reduced exercise performance in CF patients, which include reduced pulmonary function $[12,13]$, diminished nutritional status [11, 36, 37], and reduced habitual activity $[38,39]$.

Thus, there is evidence for impaired muscle function, as well as muscle quantity, being a significant factor in reduced exercise performance in CF. The origin of this impairment requires further study, although intrinsic muscle defect, poor nutrition and deconditioning due to disease severity are probably collective contributory factors.

There are few publications reviewing exercise-limiting symptoms during exercise in CF. Dyspnoea has been demonstrated to increase with increasing ventilation and work rate in CF [40, 41], just as it does in normal subjects and in other cardiorespiratory disorders [42].

The current authors have measured symptoms of breathlessness and muscle fatigue in CF subjects with a wide range of disease severity. Symptom scores for muscle effort were found to be higher than breathlessness scores in all groupings of pulmonary disease severity and that, overall, $75 \%$ of the CF subjects scored muscle effort higher than dyspnoea at peak exercise. Therefore, CF subjects perceive peripheral muscle effort as the dominant factor limiting peak exercise, supporting the current authors' conclusions from the physiological data that nonpulmonary factors predominate in limiting patients with mild-to-moderate disease. The current data are very similar to that in COPD, where median Borg scores for dyspnoea were exceeded by those for muscle effort [42]. These scores were the same as in normal controls, with muscle effort, the predominant symptom, reported as limiting progressive exercise.

There is individual variation in symptom perception, as symptom intensity was poorly correlated with either resting 
pulmonary function or any of the measurements at peak exercise. A poor correlation of dyspnoea scores with resting pulmonary function has been previously described in CF [41]. Despite this individual variation, the measurement of symptoms adds to the understanding of exercise test results and should be included in future studies of exercise in CF.

In conclusion, adult cystic fibrosis patients experience symptoms of muscle effort in excess of dyspnoea at peak exercise. They also generate high concentrations of blood lactate, similar to those observed in normal controls, but occurring at lower than normal peak workloads. Measurement of the lactate threshold is a useful way of assessing fitness and the response to interventions, such as exercise training. Peripheral factors probably predominate in limiting patients with mild or moderate disease. Pulmonary function is more important in limiting patients with severe disease, although, even then, elevated blood-lactate levels and symptom scores of muscle effort were observed. Future research studies should continue the current interest in cystic fibrosis muscle performance and, perhaps, research symptoms and muscle function at submaximal workloads, which relate more closely to everyday activities.

\section{REFERENCES}

1 Schneiderman-Walker J, Pollock SL, Corey M, et al. A randomised controlled trial of a 3-year home exerciseprogramme in cystic fibrosis. J Pediatr 2000; 136: 304-310.

2 Moorcroft AJ, Dodd ME, Morris J, Webb AK. Individualised unsupervised exercise training in adults with cystic fibrosis: a 1 year randomised controlled trial. Thorax 2004; 59: 1074-1080.

3 Godfrey S, Mearns M. Pulmonary function and response to exercise in cystic fibrosis. Arch Dis Child 1971; 46: 144-151.

4 Cerny FJ, Pullano TP, Cropp GJ. Cardiorespiratory adaptations to exercise in cystic fibrosis. Am Rev Respir Dis 1982; 126: 217-220.

5 Moorcroft AJ, Dodd ME, Webb AK. Long-term change in exercise capacity, body mass, and pulmonary function in adults with cystic fibrosis. Chest 1997; 111: 338-343.

6 Selvadurai HC, Allen J, Sachinwalla T, et al. Muscle function and resting energy expenditure in female athletes with cystic fibrosis. Am J Respir Crit Care Med 2003; 66: 1476-1480.

7 Moser C, Tirakitsoontorn P, Nussbaum E, Newcomb R, Cooper D. Muscle size and cardiorespiratory response to exercise in cystic fibrosis 2000. Am J Respir Crit Care Med 2000; 162: 1823-1827.

8 Shah AR, Gozal D, Keens TG. Determinants of aerobic and anaerobic exercise performance in cystic fibrosis. Am J Respir Crit Care Med 1988; 157: 1145-1150.

9 Klijn PH, van der Net J, Kimpen JL, Helders PJ, van der Ent CK. Longitudinal determinants of peak anaerobic performance in children with cystic fibrosis. Chest 2003; 124: 2215-2219.

10 Klijn PH, Terheggen-Lagro W, van der Ent CK, van der Net J, Kimpen JL, Helders PJ. Anaerobic exercise in pediatric cystic fibrosis. Pediatr Pulmonol 2003; 36: 223229.
11 Marcotte JE, Grisdale RK, Levison H, Ceates AL, Canny GJ. Multiple factors limit exercise capacity in cystic fibrosis. Pediatr Pulmonol 1986; 2: 274-281.

12 Coates AL, Boyce P, Muller D, Mearns M, Godfrey S. The role of nutritional status, airway obstruction, hypoxia, and abnormalities in serum lipid composition in limiting exercise tolerance in children with cystic fibrosis. Acta Paediatr Scand 1980; 69: 353-358.

13 Lands LC, Heigenhauser GJ, Jones NL. Analysis of factors limiting maximal exercise performance in cystic fibrosis. Clin Sci 1991; 83: 391-397.

14 De Meer K, Gulmans VAM, van der Laag J. Peripheral muscle weakness and exercise capacity in children with cystic fibrosis. Am J Respir Crit Care Med 1999; 159: 748-754.

15 Myers J, Ashley E. Dangerous curves: a perspective on exercise, lactate and the anaerobic threshold. Chest 1997; 111: 787-795.

16 Hjeltnes N, Stanghelle JK, Skyberg D. Pulmonary function and oxygen uptake during exercise in 16 year old boys with cystic fibrosis. Acta Paediatr Scand 1984; 73: 548-553.

17 Martin D, Day J, Ward G, Carter E, Chesrown S. Effects of breathing a normoxic helium mixture on exercise tolerance of patients with cystic fibrosis. Pediatr Pulmonol 1994; 18: 206-210.

18 McLoughlin P, McKeogh D, Byrne P, Finlay G, Hayes J, FitzGerald MX. Assessment of fitness in patients with cystic fibrosis and mild lung disease. Thorax 1997; 52: 425-430.

19 Nikolaizik WH, Knopfli B, Leister E, de Boer P, Sievers B, Schoni MH. The anaerobic threshold in cystic fibrosis: comparison of V-slope method, lactate turn points, and Conconi test. Pediatr Pulmonol 1998; 25: 147-153.

20 Killian KJ, Leblanc P, Martin DH, Summers E, Jones NL, Campbell EJ. Exercise capacity and ventilatory, circulatory, and symptom limitation in patients with chronic airflow limitation. Am Rev Respir Dis 1992; 146: 935-940.

21 Borg GA. Psychophysical basis of perceived exertion. Med Sci Sports Exerc 1982; 14: 377-381.

22 Knudson RJ, Lebowitz MD, Holberg CJ, et al. Changes in the normal maximum expiratory flow-volume curve with growth and ageing. Am Rev Respir Dis 1983; 127: 725-734.

23 Jones NL. Clinical exercise testing. 3rd Edn. Philadelphia, W.B. Saunders, 1988.

24 Cassaburi R, Patessio A, Iolli F, et al. Reductions in exercise lactic acidosis and ventilation as a result of exercise training in patients with obstructive lung disease. Am Rev Respir Dis 1991; 143: 9-18.

25 Lebecque P, Lapierre JG, Lamarre A, et al. Diffusion capacity and oxygen desaturation effects on exercise in patients with cystic fibrosis. Chest 1987; 91: 693-697.

26 Maltais F, Jobin J, Sullivan MJ, et al. Metabolic and hemodynamic responses to lower limb during exercise in patients with COPD. J Appl Physiol 1998; 84: 1573-1580.

27 Maltaise F, Simard A, Simard C, Jobin J, Desgognes P, LeBlanc P. Oxidative capacity of the skeletal muscle and lactic acid kinetics during exercise in normal subjects and in patients with COPD. Am J Respir Crit Care Med 1996; 153: 288-293.

28 Maltais F, LeBlanc P, Simard C, et al. Skeletal muscle adaptation to endurance training in patients with chronic 
obstructive pulmonary disease. Am J Respir Crit Care Med 1996; 154: 442-447.

29 Szeinberg A, England S, Mindorff C, Fraser IM, Levison H. Maximal inspiratory and expiratory pressures are reduced in hyperinflated, malnourished young adult male patients with cystic fibrosis. Am Rev Respir Dis 1985; 132: 766-769.

30 de Meer K, Jeneson JA, Gulmans VA, van der Laag J, Berger R. Efficiency of oxidative work performance of skeletal muscle in patients with cystic fibrosis. Thorax 1995; 50: 980-983.

31 Dechecchi MC, Girella E, Cabrini G, Berton G. The Km of $\mathrm{NADH}$ dehydrogenase is decreased in mitochondria of cystic fibrosis cells. Enzyme 1988; 40: 45-50.

32 Shapiro BL. Evidence for mitochondrial lesion in cystic fibrosis. Life Sci 1989; 44: 1327-1334.

33 Selvadurai HC, McKay K, Blimkie CJ, Cooper P, Mellis C, Van Aspen P. The relationship between genotype and exercise tolerance in children with cystic fibrosis. Am J Respir Crit Care Med 2002; 165: 762-765.

34 Hussey J, Gormley J, Leen G, Greally P. Peripheral muscle strength in young males with cystic fibrosis. J Cyst Fibros 2002; 1: 116-121.

35 Elkin SL, Williams L, Moore M, Hodson M, Rutherford OM. Relationship of skeletal muscle mass, muscle strength and bone mineral density in adults with cystic fibrosis. Clin Sci 2000; 99: 309-314.
36 Marcotte JE, Canny GJ, Grisdale R, et al. Effects of nutritional status on exercise performance in advanced cystic fibrosis. Chest 1986; 90: 375-379.

37 Boas SR, Joswiak ML, Nixon PA, Fulton JA, Orenstein DM. Factors limiting anaerobic performance in adolescent males with cystic fibrosis. Med Sci Sports Exer 1996; 28: 291-298.

38 Boucher GP, Lands L, Hay JA, Hornby L. Activity levels and relationship to lung function and nutritional status in children with cystic fibrosis. Am J Phys Med Rehab 1997; 76: 311-315.

39 Nixon PA, Orenstein DM, Kelsey SF. Habitual activity in children and adolescents with cystic fibrosis. Med Sci Sports Exer 2001; 33: 30-35.

40 O'Neill PA, Dodds M, Phillips B, Poole J, Webb AK. Regular exercise and reduction of breathlessness in patients with cystic fibrosis. Br J Dis Chest 1987; 81: 62-69.

41 De Jong $W$, van der Schans CP, Mannes GP, van Aalderen WM, Grevink RG, Koeter GH. Relationship between dyspnoea, pulmonary function and exercise capacity in patients with cystic fibrosis. Respir Med 1997; 91: 41-46.

42 Hamilton AL, Killian KJ, Summers E, Jones NL. Symptom intensity and subjective limitation to exercise in patients with cardiorespiratory disorders. Chest 1996; 110: 12551263. 